\title{
Analysis of the Basic Methods of Red Design in Modern Design Symbols Liang Cheng
}

\author{
School of Arts, East China University of Technology, Nachang, Jiangxi Province, 344000
}

\author{
Keywords: Red design; Red element; Red culture; Modern art design
}

\begin{abstract}
Red design is a very unique design theme, containing a large amount of information. It is a design which brings a revolutionary atmosphere in the traditional design language style. As a kind of cultural design, it enriches the cultural connotation of modern art and design. Today, we organically combine red design with modern art design so that red elements will still shine brightly today.

This paper starts from the red design, takes the red element as the research object, actively explores the complementary topic between the red design and the modern art design in our country, attempts to by the dotted section discuss the advantage and the present situation of the red culture in the modern design and the basic methods of red design following in modern design, the research characteristics of red design in modern art design, the refining of red design in the modern design and the integration of red design elements in modern design elements, etc. This paper enables designers to actively understand and grasp the characteristics of China's red design, correctly understand the geographical environment, cultural characteristics, and national spirit of China in order to break through the thinking mode of predecessors who only analyze the revolution and popularity of red design. At the same time, this paper also attempts to demonstrate the feasibility of the fusion of red design and modern art design with concrete examples.

The red design is one of the outstanding cultures that create the inheritance in the history of new China in our country. Red design today is a spiritual symbol of an era and it is affecting the way of thinking and daily life of the masses at any time and place.
\end{abstract}

\section{Introduction}

Red culture is a typical regional culture in our country. It has a great brilliant and glorious revolutionary tradition. For example, the glorious August $1^{\text {st }}$ Nanchang Uprising happened in Jiangxi Province, as well as famous revolutionary base of Jinggang Mountains and Central Soviet Area. With the emergence and development of the red culture trend in our country, designers once again discover the traditional culture of history and some designs related to red culture, and arouse a strong emotion and use a variety of design performance techniques with a distinctive red design characteristic. The design related to modern red culture that is compatible with modern life and culture is once again aroused. In this context, based on the traditional red culture and design, the subject reconstructs and integrates the traditional red culture and design and modern art design. ${ }^{[1]}$

The trend of China's red culture research can be traced back to around 1980, when it was just the early stage of reform and opening up and the social and economic growth was rapid. Under such a phenomenon, red culture is under the spotlight of everyone. It carries the glorious revolutionary history of our party and possesses strong characteristics of the times and regions. ${ }^{[2]}$ In recent years, some experts and scholars have studied the ways of development of "red culture" and many achievements have been made both at home and abroad. These achievements form the basis for the study of this topic, in which the more representative of academic achievements are as follows. Art History of Central Soviet Area (1999) by Scholar Lin Daofu comprehensively and deeply analyzes and summarizes the development trend of fine arts of Central Soviet Area, and the creation and the significance of history of fine arts, which "fill the gaps of the history of Chinese modern art". History of the Soviet Republic of China (China Literature Press, 2004) by Scholars Shu Long and Ling Buji, Chinese New Democracy Revolutionary Art Activities (Shanghai Painting and Calligraphy Press, 2006) by Scholar Huang Ke, as well as the master paper of Scholar Wang Dong named Research on Red Design and Hakka Culture in Central Soviet Area also have done a lot of 
research on red culture. However, with the new red cultural relics and red ruins discovered in succession, together with the rapid development of art design disciplines, as people's demands for red knowledge gradually increases, the current research in design and other aspects and the research and comparison of design on red culture are still at a relatively slow speed or even at a standstill. How to combine the red cultural elements with the modern art design is a question worthy of study. The design of red works in our country does not have corresponding design chain; especially there is a lack of new elements in the specific design of the creative, leading to low grade, being easy to counterfeit, and no features of red design works. The pattern of red design works is single and similar. The red designs of all over the country are the same and there are no changes from a dozen years ago without newborn elements. ${ }^{[3]}$

Why did this happen? There are the following reasons. Firstly, there is a lack of awareness of innovation. The concept of design and development relatively lags behind the foreign countries. Designers always think that the red should be the old tradition. As long as it is the traditional, it should be a static state of existence. They insist on tradition and old fashion and they resist innovation or reform of red works. Another point is that quite a few designers in our country have not seen the potential of technological development of the red design, let alone the establishment of a specialized institution for the development of red culture, resulting in a lack of professional strength for the development of the red design. Furthermore, the market demand analysis of the current red design works is not good, and designers of the current red design works are more or less constrained by the cost and some objective conditions. Designers just manufacture and sell their products according to their own design, not caring about the sales or customer preferences. They just ignore opinions and feedback of customers. It is a contrary to the laws of the development of design works, which ultimately leads to the low brand efficiency.

First of all, the red culture does not form a large-scale industrialization. Of course, this is also due to the fact that most of red culture in our country is in the old revolutionary base areas. Compared with other regions, the industrial development is slow and the production staff is relatively unprofessional and not concentrated. Most of red design works are still kept in the production mode of small workshops, where it is difficult to modernize the production process widely, relying on the original manual production. The hand-style workshop production of arts and crafts are not enough skilled and the production is also lack of exquisite, all of which are some simple and poor manual works. ${ }^{[4]}$

The second is that the standard of red production is not consistent. As the majority of family-run production and the scale of production is not focused on the inferior technology, which brings the development of production standards many difficulties. The lack of a unified standard also restricts the expansion of production scale and the improvement of the quality of production. The existence of such realistic problems will inevitably affect the economic benefits of red design works, which further restricts the design and development of red works.

Based on the above advantages and problems of red design, we should identify the design positioning and production patterns, create and produce new red design work.

\section{Cultural elements and Design Entities Combined Design Method}

The concept of culture is a broad concept that does not only cover the historical geography and customs of a country or a nation, but also its customs and ways to produce and live, including its ways of thinking, literature and art, codes of conduct and even values. The red design work usually represents the material life and spiritual life of a local cultural life, reflects the living status and cultural status of local people, and is a miniature version of the local cultural life. ${ }^{[5]}$

The design process of the work is actually the process of integrating the local material culture and spiritual culture, refining and processing to design another culture. The design process itself is a cultural design process. Culture is constantly evolving, innovating, settling and accumulating in sedimentation during the process of human development. The essence accumulated by this constant precipitation is often called the essence of culture. ${ }^{[6]}$ If the red design work has the essence of this culture, it will become a symbol of the local and even the country representatives. Cultural people 
will see the development of a region or even a country from which it will certainly be a representative material carrier.

And the element is something that let us see it but think of something else. For example, as long as we refer to the red culture in Hebei, we always think of Xibaipo, Langya, Baiyangdian and Ranzhuang battles that belong to this region. These regional cultural attractions seem to be the red cultural representatives and signs of Hebei, which comes out in people's minds like elements. An element is a token of human thought that conveys the full meaning of what it represents. The red culture is able to bring people the physical experience and spiritual baptism. A symbolic meaning of an abstract element is attached to the design of red cultural works, making the red culture to be continued.

Nowadays, in many places, we can see tourists from all over the world. In red culture areas, there are also tourists who are from all over the world. Many international tourists are wondering about the development of China and the Chinese Communist Party. They may also unexpectedly know about their own country, such as the international friends such as Kudrin and Bethune during the war years who came to China to support the revolution. International tourists who visit Red Cultural Scenic Area will also look for some red design works representing the unique cultural elements of the locality intentionally or unintentionally. They bring many Chinese red design works to their own countries, and promote Chinese characteristics culture and red design works. Therefore, if we can discover the artistic resources that represent the cultural elements of our country of international tourists, it will certainly be a meaningful thing.

The design of red works can also take into consideration the psychological needs of international tourists, integrate local cultural information with international cultures, adhere to the integration of ethnic groups and localities and make the international tourists feel psychological agreement. The red works designed according to this kind of thinking will be more international and cultural identity, not only to narrow the distance between each other, but also to add a new way of communication. The themes reflected in the design of red works show the different local characteristics simultaneously with the historical events of local revolution. Only in this way can red design works have the attraction of purchase, a certain memorial and collection value. The theme of the history of revolution can be historical leaders, revolutionary relics, architecture, historical texts and so on. For example, Chairman Mao chapters with a variety of materials, history books about the history of revolution, as well as historical military toys. ${ }^{[7]}$ Therefore, the design of red works should not only play the role of education but also take into account the artistic and local characteristics. Red design works shall not only have novel styles, but also profound meaning and exquisite quality with maximum value.

In the design of red works, it is worthy of designers' attention to the development of red works, especially the cultural meanings with unique meanings, so that red works can play a profound educational role on people. To make the red cultural characteristics strongly reflect in design work, it should be reasonable to use the elements of the local culture to represent the elements, so there will be a multiplier effect. Designers of red design works should gradually strengthen their own cultural levels, increase the reading of red culture, understand more deeply the tradition of our country's revolutionary history, and carry forward the great spirits of our revolutionary predecessors through the design of red design works.

\section{Regional Characteristics and Folk Traditions of the Combination Design Method}

Regional resource characteristics include geographical and natural resources and cultural resources. The majority of red color designers shall fully consider the use of the local regional resources characteristics.

China is a country which is rich in natural resources and diverse folk art traditions across the country. For example, there are Quyang stone carvings, Yuxian paper-cuttings, Baigou clay-plants and reeds, etc., which are widely spread in Hebei. The traditional folk arts and crafts of our country are mostly made of local natural raw materials and do not need to go abroad to buy goods. What's more, the traditional handmade technology makes red design works have a naturally clever and 
rustic beauty with strong local characteristics unique ethnic style. The local culture in the traditional folk craft is a precious gift from a long history. We must not only inherit it, but also incorporate it into the design of the local red works. Inspired by the endless inspiration, designers will make red design works have a different kind of aesthetic taste and value.

When designing red works, designers can skillfully combine the features of local natural resources with the local folk traditional craftsmanship, try to examine them from different aspects as much as possible, and combine together local topography, biological climate, architectural artifacts, historical relics, local customs and practices, folk culture and other factors. After mastering more specific information, designers shall analyze, combine and reconstruct the information to begin with the effective selection of the processing design and finally determine the design elements, design plans and design priorities. ${ }^{[8]}$

Therefore, the design of red works can also be described as a huge system engineering project. It is not a single imagination of a single piece of work, or a gratuitous design process. Designers shall combine the natural resources of region and traditional crafts effectively together, and the design of red works should be a systematic design task of collecting information, processing and handling. Only the interlocking design will make red design work not only have regional resources but also rich connotation and style.

\section{Reform Innovation and Low-carbon Design Method}

Nowadays, green low-carbon design is no longer a fresh topic. The design of red works is very spiritual and cultural connotation and innovative. During the design process, designers must not abandon the low-carbon design concept and carry out activities contrary to the natural ecology or make extremely luxurious and wasteful design. If the designer's red work can be recycled, it is the highest level of today's red design. For the design works with red features, reform and innovation shall be taken as the soul of the design. For the red design work, the first of all is to have the original intention of reform and innovation. If the design also has green awareness of low-carbon, it will be the leap of the essence in design quality.

In fact, the ultimate goal of design is for people, of course, the design of red works is the same. It does not only carry the human pleasure and memory with the purpose of using, and the red design work also has the purpose of memory, respect, and solemn of revolutionary feelings. A luxuriant red design project runs counter to the current green and low-carbon way of life, which does not only fail to convey the simple and honest feelings of people who admire the revolutionary martyrs, but also undermines the devout heart the majority of people. Therefore, designers should stick to the original consciousness of reform and innovation and the awareness of low-carbon while conducting red design.

The low-carbon style is advocated vigorously by modern society. Many fields in our country are trying their best to make the only planet on which we live to become more harmonious. As long as we strive to change the bad habit of damaging the earth, the Earth also gives us a better survival environment. The rumors that once predicted the destruction of the earth will never realize. Today, many new advances in science and technology allow us to have many new low-carbon raw materials. Designers will use more low-carbon raw materials for the design of red works, so that the design of red works is both low-carbon and original. These works are very popular in the market and the vitality of red culture will be a greater limit of continuity.

However, the quality of design works must be cleared. One-time work cannot be designed, resulting in a lot of waste of resources. Discarding one-time works will also create an unnecessary burden on the environment. Therefore, when designers design red works, they should reflect the green low-carbon value of their works and ensure the quality so that people will not feel disappointed with red design works. After all, these works are also the best material evidence to prove that they have ever been to. The works shall be preserved in a long time. 


\section{Enhance the Level and Highlight the Brand Combination Design Method}

At present, the key to the development of red works design lies in how to highlight the brand. In the vast land of China, there are rich red cultural resources all over the country. It is not easy for red design works to be unique in many cultural works. Designers should have the awareness of prominent brands and improve the skills of reforming and reforming red cultural works, only by this way will maximize the added value of red design works. To increase efforts to improve investment of the quality and marketing strategy of red design works can enhance the visibility and the overall competitiveness of industry of China's red design work in the country and the world, so as to promote the brand awareness of the entire red design work so that the cultural work can continue to develop healthily.

How can we highlight the brand awareness of red design? We can consider the introduction of CI design. Taking cultural market as a business, CI domain system model can be used to highlight the optimization of the red design market, in order to achieve better brand effect. If it involves the aspects of the design of the work, designers can learn from the perspective of VI to enhance their own levels of red design issues, to better disseminate the red design work.

The natural resources of China's red design are very rich, represented by Hebei, Henan, Shaanxi, Hunan, Hubei and Jiangxi. There are many mountains, lakes and beautiful natural landscapes with rich natural resources. They are one of the best resources for designers to combine green eco-design with modern red design, such as Jinggangshan bamboo, rhododendrons, Baiyangdian reeds, etc. These are very original with the geographical characteristics of the material basis. China's red culture is an advanced culture with Chinese characteristics created by a group of Chinese communists and working-class people in a special revolutionary era. It contains a strong revolutionary spirit and a profound historical culture connotation.

Most of the red cultural resources in our country have inherited the revolutionary spirit of the old areas in a concentrated manner and have preserved the positive energy of the Communist Party of China, the party spirit of the Chinese Communist Party and its fine traditional style. The red culture of our country contains a large amount of material resources, such as the red traces, sites, relics, architecture, various kinds of facilities and other material resources left behind during the revolutionary period, including some important revolutionary red cultural relics and even some important literary and art works. There are also some non-material red resources, such as Yanan Spirit, the Long March Spirit and the Jinggangshan Spirit, which have always admired some important red revolutionary spirits.

This paper is one of the phased achievements of humanities and social sciences projects in Jiangxi Province of 2016 Image Symbolization of Red Culture in Modern Design (Project No. YS161007).

Cheng Liang (1982-), male, lecturer, graduated from Fine Arts College, Hebei Normal University (Undergraduate), Art Institute, Qingdao University (Master), currently teaching at Arts Institute of Donghua University. During the teaching period, he published more than 20 papers (works), including $10 \mathrm{CSSCI}$ and core periodicals (works), participated in 6 provincial-level topics, presided over 2 provincial and city-level topics, presided over one of the school-level topics, won the provincial teaching achievement third prize, city (hall) grade third prize, guided students to participate professional competition for more than 10 times.

\section{Cnclusion}

Today people's demand for red culture has been diversified and pure red design work has been far from meeting people's psychological needs. People's red complex determines their longing for the red culture and the pursuit of red elements carry too much red revolutionary spirit and historical and cultural heritage, which is why they aspire to red culture. A geographical and historical culture is a distant historical relics, which needs our protection and inheritance. A long historical era is people's vision and longing. Designers should pay attention to add red elements that can restore historical scenes. Such a red design is worthy of reference and application, which is not only because of the fact of respecting the red culture itself, but also due to its close connection with modern art design. 


\section{References}

[1] Hebei Province Red Tourism Product Design and Development Research. Ma Jie[D], Hebei University of Science and Technology, 2012.

[2] Inheritance and Creation-Application Research of Landscape Design Art in Jiangxi Red Tourism Scenic Area. Hu Xiaocong[D], Nanchang University, 2007.

[3] On "Red Culture" Symbol in Contemporary Commercial Graphic Design. Shao Luyun[D]. Suzhou University, 2009.

[4] Development and Design of Red Tourism Souvenir, Wei Xiaoying[D], Hebei University, 2007. 5 On the Application of Red Cultural Elements in Interior Design. Tang Shiqi[M], Huazhang, 2014, No. 2.

[5] Central Soviet Area Red Design and Hakka Culture Research. Wang Dong[D], Jiangnan University, 2008.

[6] On the Development of Red Tourism of Nanchang. Xu Xiaojin[M], Nanchang College Journal, 2005, No. 5.

[7] On the Characteristics of Red Design in Central Soviet Area. Wang Dong[M], Packaging Engineering, 2007-11.

[8] A Review of the Study of Red Cultural Resources from the Perspective of Region, Yuan Dongmei[M] ,Youth and Society, 2012, No.2. 